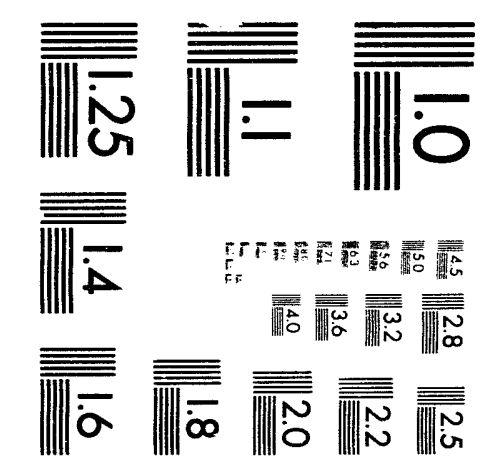



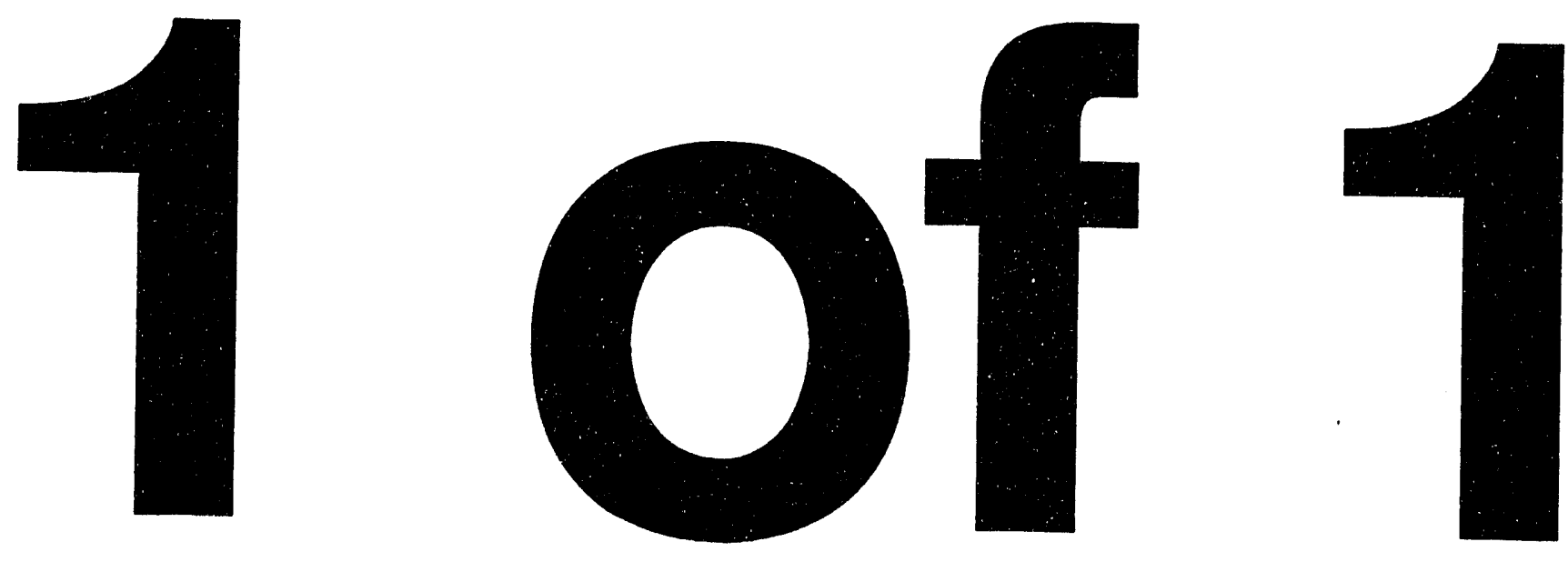


\title{
Initial Ultraviolet-B Intensity Data at Lawrence Livermore National Laboratory
}

\author{
K.O. Patten
}

D.J. Wuebbles

G.J. Smith

October 1993

Ihis is an informal report intended primarily for internal or limited external distribution. The opinions and conclusions stated are those of the author and may or may not be those of the Laboratory.

Work performed under the auspices of the U.S. Department of Energy by the Lawrence Livermore National Laboratory under Contract W-7405-Eng-48. 


\section{DISCLAIMER}

This document was prepared as an acccount of work sponsored by an agency of the United States Government. Neither the United States Government nor the University of California nor any of their employees, makes any warranty, express or implied, or assumes any legal liability or responsibility for the accuracy, completeness, or usefulness of any information, apparatus, product, or process disclosed, or represents that its use would not infringe privately own rights. Reference herein to any specifie commercial products, process, or service by trade name, trademark, manufacturer, or otherwise, does not necessarily constitute or imply its endorsement, recommendation, or favoring by the United States Government or the University of California. The views and opinions of authors expressed herein do not necessarily state or reflect those of the United States Government or the University of California, and shall not be used for advertising or product endorsement purposes.

This report has been reproduced

directly from the best available copy.

Available to DOE and DOE contractors from the

Office of Scientific and Technical Information

P.O. Box 62, Oak Ridge, TN 37831

Prices available from (615) 576-8401, FTS 626-8401

Available to the public from the

National Technical Information Service

U.S. Department of Commerce

5285 Port Royal Rd.,

Springfield, VA 22161 


\title{
Initial Ultraviolet-B Intensity Data at Lawrence Livermore National Laboratory
}

\author{
Kenneth O. Patten, Jr. and Donald J. Wuebbles \\ Lawrence Livermore National Laboratory \\ Gerald J. Smith \\ New Zealand Institute for Industrial Research and Development \\ PO Box 31313, Lower Hutt, New Zealand
}

\section{Introduction}

Ultraviolet-B radiation (UV-B), in the $290-350 \mathrm{~nm}$ wavelength region, produces both sunburn and skin cancer in humans (White et al., 1993, and references therein). Since the intensity of UV-B at the ground is expected to increase with stratospheric ozone depletion, measurements of UV-B which could confirm this would be usefui in both science and policy. Past measurements of ground UV-B intensity in the United States were obtained using a network of Robertson-Berger radiometers. Robertson-Berger radiometers, however, have been found to degrade with exposure to UV-B, so that calibration and intercomparison of the meters is necessary in order to apply these measurements to long-term trends and correlations. The past measurements generally neglected calibration and intercomparison. New measurements of ground UV-B are needed.

A measurement of UV-B reaching the ground has been established at the Lawrence Livermore National Laboratory. The instrument is the same as those operated by the National Institute for Water and Atmospheric Research in their network in New Zealand (White et al., 1993). The wavelength response of the radiometer is similar to the response of human skin to UV-B. Intensity data are collected by averaging meter readings over 10 minutes from 6:00 am to 6:00 pm Pacific Standard Time, then converting to effective UV-B intensity normalized at $310 \mathrm{~nm}$ in accord with White et al. (1993).

This report checks the intensities obtained at LLNL from November 1992 to July 1993 against the expected results:

-Increased solar zenith angle, whether from the daily cycle or from the yearly cycle in solar position, should decrease UV-B intensity at the ground due to increased optical path;

-Intervening cloud cover should decrease ground UV-B intensity.

Three additional findings are reported here:

- Maximum UV-B intensity on cloudless days does not always follow a smooth curve, but instead varies either high or low to some extent; 
- Morning UV-B intensities are less than those in the afternoon at comparable solar zenith angles at certain times of year;

-LLNL wintertime daily-averaged UV-B intensities are somewhat higher than those observed at Auckland, New Zealand in their winter of 1992.

Further analysis of these findings will require data over more time. The LLNL UV-B intensity measurements, plus those from New Zealand, will be compared with satellite measurements of trace gases, aerosols, and radiation and with ground measurements of meteorological properties in order to determine:

-full year-round trends in ground UV-B intensity, both peak and average;

-effect of trends in radiatively active atmospheric trace gases and aerosols, particularly stratospheric ozone and volcanic aerosols, on ground UV-B;

-possible differences between Northern and Southern Hemisphere subtropical latitudes arising from the Antarctic "ozone hole".

In parallel, numerical models of the radiative transfer determining UV-B intensity have been developed to aid the understanding of the measurements.

\section{Results}

Figure 1 displays the trend in ground UV-B with respect to date by month from November 1992 (Figure 1A) to July 1993 (Figure 1I). Each day contains 70 or more ground UV-B measurements. Several days have intensity maxima considerably less than other days within the month (example: January 17-19 in Figure 1C). Th $\cdot$ days are most commonly found to have cloud cover over the measurement site from the time-of-day profile (see below). Among clear days, the peak values of UV-B generally abide by the expected trend: decreasing throughout November (Figure 1A), reaching a minimum near December 22, the Northern Hemisphere Winter Solstice (Figure 1B), then increasing as days proceed in January through July (Figures 1C to 1I). However, several groups of adjacent days show possible local deviations; two examples occur on January 9-11 (Figure 1C) and March 22 (Figure 1E).

Average and maximum UV-B intensities are plotted against Julian Day (index of the day in the year; Julian Day 1 is January 1) 1993 in Figure 2. Figure 2A, the daily average UV-B intensity, exhibits clouds through the downward "spikes" extending below the general profile, an inverted parabola centered approximately on December 22. A "bump" of intensity some 10 percent above the general trend $\left(11 \mu \mathrm{W} \mathrm{cm} \mathrm{cm}^{-2}\right.$ vs. $\left.10 \mu \mathrm{W} \mathrm{cm} \mathrm{cm}^{-2}\right)$ is noted immediately after December 22. The suspected local peak on March 22 is also demonstrated against the general parabolic profile. Clouds apparently have less relative effect on the daily maximum intensity, plotted in Figure 2B. Here, the "bump" of higher intensity after December 22 
appears, as does the one-day "spike" on March 22, although that date is followed by several consecutive days of cloudiness. Figure $2 \mathrm{C}$ illustrates the daily maxima of UV-B intensity against solar zenith angle at the maximum intensity. This envelope exhibits a maximum range except for the "spike" of March 22.

Figure 3 illustrates the intensity versus Pacific Standard (USA) Time of data collection for three days in November 1992: the 6th and 30th (clear), and the 19th (cloudy). Little intensity is detected before 7:00 am or after $5: 30 \mathrm{pm}$, as expected for nighttime, and the intensity reaches its peak near local noon on the two clear days. Intensity has decreased on the 30th (dashed line) compared with the 6th (solid line) at all times of the day due to seasonal variation as demonstrated in Figures 1 and 2 . The profile of the cloudy day (dotted line), on the other hand, does not exhibit the same symmetric form of the clear days, instead varying erratically throughout midday. This erratic profile indicates cloudiness, so that those data are excluded from further interpretation.

Based on the LLNL longitude of $121^{\circ} 42^{\prime} 55^{\prime \prime} \mathrm{W}$, the maximum of intensity (local noon) is expected to occur approximately eight minutes after noon Pacific Standard Time. Figure 4A demonstrates UV-B intensity versus time of day for a clear day in November shown in Figure 3, June 20, 1993, and two clear days in March, the 5th and the 22nd. The November day and the June day have intensity maxima nearly at local noon (dotted vertical line); this is typical of days in those two months. The two March days have maxima one-half hour after local noon. This asymmetry is only apparent in March and April data so far.

A clearer view of the variation from local noon by the maximum of intensity is provided by plotting intensity against solar zenith angle. Given the LLNL latitude of $37^{\circ} 41^{\prime}$ $36^{\prime \prime} \mathrm{N}$ and its longitude, the expected solar zenith angle over LLNL is determined at any given day and time from a formula given by Paltridge and Platt (1976). Figure 4B shows intensity versus solar zenith angle for the four dates in Figure 4A. For the November and June days, morning intensities are nearly the same as afternoon intensities at the same solar zenith angle. However, the March days show intensity maxima at a greater angle than the minimum solar zenith angle achieved, and the afternoon intensities are typically 10 to $20 \mu \mathrm{W}$ $\mathrm{cm}^{-2}$ greater than morning intensities at the same solar zenith angle. Asymmetries about local noon have been noted in $320 \mathrm{~nm}$ ground intensity data at Reading, England, United Kingdom in July and September 1990 by Webb (1991), except that the morning intensities were higher there than in the afternoon.

Figure $4 \mathrm{~B}$ also demonstrates a potential dependence on seasonal ozone concentrations and other factors. The intensity of UV-B at a given solar zenith angle is highest for the November day, lower for the March days (although the afternoon intensities are nearly as high as in November), and lowest for June. Ordinarily, spring is the time of maximum stratospheric ozone, so that UV-B intensities should be lower in March than November. The still lower UV-B in June may be due to boundary layer pollution and dust over Livermore.

Daily maximum UV-B intensities for 1992 from the New Zealand measurement site in 
Auckland are compared with the daily maxima of LLNL in Figure 5. In order to align the data, the horizontal axis taken is the day number after the local winter solstice (June 22 for the New Zealand site). The LLNL intensities (solid line) are significantly higher than any of the New Zealand data throughout the year, despite the similar absolute values of the latitudes of LLNL and Auckland. This comparison is preliminary, and further comparisons will be done in order to confirm this result.

\section{Future Work}

The measurements of November 1992 through July 1993 cover approximately twothirds of a year. Measurements in the longer term are required in order to produce conclusions about UV-B intensity and ozone column at LLNL. These additional data will especially assist in the comparison with New Zealand summer in light of the result of Figure 5, which indicates that UV-B is less there than at LLNL for 1992 despite the Antarctic ozone hole.

Yearly re-calibration of the UV-B radiometer is recommended. Currently, it is planned to return the radiometer to New Zealand after summer. However, transit time and administrative hurdles could severely slow the return of the radiometer for further measurements. An inquiry has been made to ARAC as to whether LLNL has local provisions for both an absolute calibration of response by wavelength against a standard light source and relative calibration of its response against geometric position of light source. A response to this inquiry is awaited.

Intercomparison with other measurements has been demonstrated as a necessity in the UV-B intensity studies. Two additional LLNL measurements are soon to be underway. A second UV.B radiometer has been obtained by our group and is to be installed near the original radiometer for simultaneous measurements. The Engineering Department at LLNL has obtained a UV-B spectrophotometer, which we plan to set up to measure UV-B intensity as a function of wavelength for a further check on our measurements. The latter measurement will be especially useful for the testing of the UV-B model discussed below.

As has already been observed in the winter 1992-3 measurements, clouds reduce the UV-B intensity at LLNL. An additional possible correlation is that aerosols and dust near the ground at Livermore should serve to scatter UV-B, thus reducing our measured intensities. Either is expected to reduce the total solar radiation observed at the surface, and two measurement towers at the West Gate site operated by the Environmental Characterization and Integrated Assessment Group, Health and Ecological Assessment Division, Geoscience and Environmental Research Program have taken measurements of wind speed and direction, temperature, and solar radiation in the $300 \mathrm{~nm}$ to $3 \mu \mathrm{m}$ range. Of these data, the total radiation should be decreased in proportion to the cloudiness and turbidity between the sun and LLNL. Fast winds from the west are expected to prevent the accumulation of particulates near the ground, while slow easterly winds can allow particulates to persist. Unusually high temperatures allow both particulate and gaseous pollutants to accumulate near the ground 
when thermal inversions occur. A request for these data has been made and is pending as of this date.

Ultimately, we plan to analyze the expected inverse correlation between ozone column and UV-B intensity at the ground. Figure 6 shows a calculation, using parameters from the LLNL 2-D chemical-radiative-transport model of the troposphere and stratosphere (Johnston et al., 1989; Wuebbles et al., 1991), of the UV-B intensity expected to reach the ground at 30 ${ }^{\circ} \mathrm{N}$, local noon on the Spring Equinox. This estimate includes only ozone absorption and does not account for aerosols or clouds. The profile in the standard case (solid line) is consistent with recent LLNL spectroscopic nbservations (Armatis et al., private communication) and with other observations of UV-B dispersed spectra (Webb, 1991; Seckmeyer and McKenzie, 1992; McKenzie et al., 1992). A decrease in ozone concentration of five percent at all altitudes (dashed line) causes insignificant changes in UV-B intensity except for wavelengths less than $300 \mathrm{~nm}$. At $290 \mathrm{~nm}$, the most harmful wavelength biologically among those considered, the ground intensity doubles. The profiles can also be convoluted with the spectral response of the radiometer; the standard case produces an erythemally effective UV-B intensity of $390 \mu \mathrm{W} \mathrm{cm} \mathrm{cm}^{-2} \mathrm{~nm}^{-1}$ at $310 \mathrm{~nm}$, while the five percent loss case produces $420 \mu \mathrm{W}$ $\mathrm{cm}^{-2} \mathrm{~nm}^{-1}$ at $310 \mathrm{~nm}$. Peak measurements of $200 \mu \mathrm{W} \mathrm{cm} \mathrm{cm}^{-2} \mathrm{~nm}^{-1}$ at $310 \mathrm{~nm}$ in LLNL summer reveal that the clear-sky approximation used in the calculation markedly overestimates UV intensity, but the calculation shows that UV-B increases due to ozone loss should be detected with this radiometer.

Correlation of UV-B intensity with ozone column and concentration may prove difficult in practice (likely to need evaluation of other gases and aerosols). Figure 7 illustrates the result of an initial comparison of UV-B data with NIMBUS-7 TOMS (Total Ozone Mapping Spectrometer) column ozone data at the time of the anomalous UV-B peak on March 22, 1993. The peak UV-B intensity on March 22 is nearly 20 percent higher than that on March 20, but the column ozone on the two days is essentially identical. Both days were visually clear, so that other factors not understood to date are responsible for the March 22 UV peak. Further studies of UV-B correlation with ozone will use data from the Upper Atmosphere Research Satellite as well as TOMS.

Simultaneously with these experimental and analysis efforts, a special version of our radiative transfer models has been adopted for detailed analyses of UV-B intensity. This model version is based on previously created radiation models, but has been modified for particular emphasis on the $290-350 \mathrm{~nm}$ wavelength region with higher resolution and allow for aerosol and cloud effects.

\section{Acknowledgments}

This work was sponsored by the Laboratory Directed Research and Development Program at Lawrence Livermore National Laboratory. KP also appreciates appointment to the Global Change Distinguished Postdoctoral Fellowships sponsored in part by the U.S. 
Department of Energy, Office of Health and Environmental Research, and administered by Oak Ridge Associated Universities. The authors appreciate the work of Ed Bush on setting up and checking the instruments used on this project and thank Rich Stolarski and Eric Beach of Goddard Space Flight Center for permission to use NIMBUS-7 TOMS data in this report prior to publication.

\section{References}

H. S. Johnston, D. E. Kinnison, and D. J. Wuebbles, 1989: "Nitrogen Oxides from High-Altitude Aircraft: an Update of Potential Effects on Ozone", J. Geophys. Res. 93, 16,351-63.

R. L. McKenzie, P. V. Johnston, M. Kotkamp, A. Bittar, and J. D. Hamlin, 1992: "Solar Ultraviolet Spectroradiometry in New Zealand: Instrumentation and Sample Results from 1990", Appl. Opt. 31, 6501-9.

G. W. Paltridge and C. M. R. Platt, 1976: Radiative Processes in Meteorology and Climatology (Elsevier), pp. 61-3.

G. Seckmeyer and R. L. McKenzie, 1992: "Increased Ultraviolet Radiation in New Zealand $\left(45^{\circ} \mathrm{S}\right)$ Relative to Germany $\left(48^{\circ} \mathrm{N}\right) "$, Nature 359, 135-7.

A. R. Webb, 1991: "Solar Ultraviolet Radiation in Southeast England: the Case for Spectral Measurements", Photochem. Photobio. 54, 789-94.

M. G. White, G. J. Smith, K. G. Ryan, R. B. Coppell, D. Backshall, C. J. Edmunds, and R. L. McKenzie, 1993: "Erythemal and Carcinogenic Ultraviolet Radiation at Three New Zealand Cities 1989-1990", preprint submitted for publication.

D. J. Wuebbles, D. E. Kinnison, K. E. Grant, and J. Lean, 1991: "The Effect of Solar Flux Variations and Trace Gas Emissions on Recent Trends in Stratospheric Ozone and Temperature", J. Geomagn. and Geoelectr. 43, Suppl., 709-18.

\section{Figure Captions}

Figure 1. Effective erythemal intensity (normalized at $310 \mathrm{~nm}$ ) observed at LLNL versus day of the month for: (A) November 1992; (B) December 1992; (C) January 1993; (D) February 1993; (E) March 1993; (F) April 1993; (G) May 1993; (H) June 1993; (I) July 1993. Note that the upper limit of the intensity scale varies from month to month.

Figure 2. Three measures of UV-B intensity for each day are plotted: (A) average intensity over the day against 1993 Julian day; (B) maximum intensity during 
the day against 1993 Julian day; (C) maximum intensity during the day against minimum solar zenith angle.

Figure 3. Effective UV-B intensity is plotted against the time of day (Pacific Standard, U. S.) for three days in November 1992. Clear days: (solid) the 6th, (dashed) the 30th; cloudy day: (dotted) the 19th.

Figure 4. (A) A clear day from Figure 3 (dash-dot $=$ November 6 ) and the clear day June 20, 1993 (solid) are compared with two clear days from March 1993 (dashes = March 5; dash-3 dots = March 22) in a plot of intensity versus time of day. Note the dotted line illustrating the expected local noon, the symmetry of the November and June days about that line, and the asymmetry of the March days with respect to that line. (B) Plot of intensity versus solar zenith angle for the days in (A), which highlights the asymmetry in the March days.

Figure 5. Comparison of daily maximum erythemally effective intensity between the LLNL measurements (solid) and measurements from Auckland, New Zealand in 1992 (dashed) versus day after the 1992 Winter Solstice (for LLNL, day $0=$ December 22, 1992; for New Zealand, day 0 = June 22, 1992).

Figure 6. Upper section: Predicted UV-B spectrum based on LLNL 2-D chemicalradiative-transport model at the ground at $30^{\circ} \mathrm{N}$, local noon, Spring Equinox. Solid line: $\mathrm{O}_{3}$ from model; dashed line: $\mathrm{O}_{3}$ of model reduced by five percent at all altitudes. Lower section: Ratio of UV-B intensities predicted for a five percent loss of $\mathrm{O}_{3}$ at all altitudes.

Figure 7. Comparison of LLNL UV-B intensity data and NIMBUS-7 TOMS column ozone measurements at $37.5^{\circ} \mathrm{N}, 121.875^{\circ} \mathrm{W}$ in the second half of March 1993. 


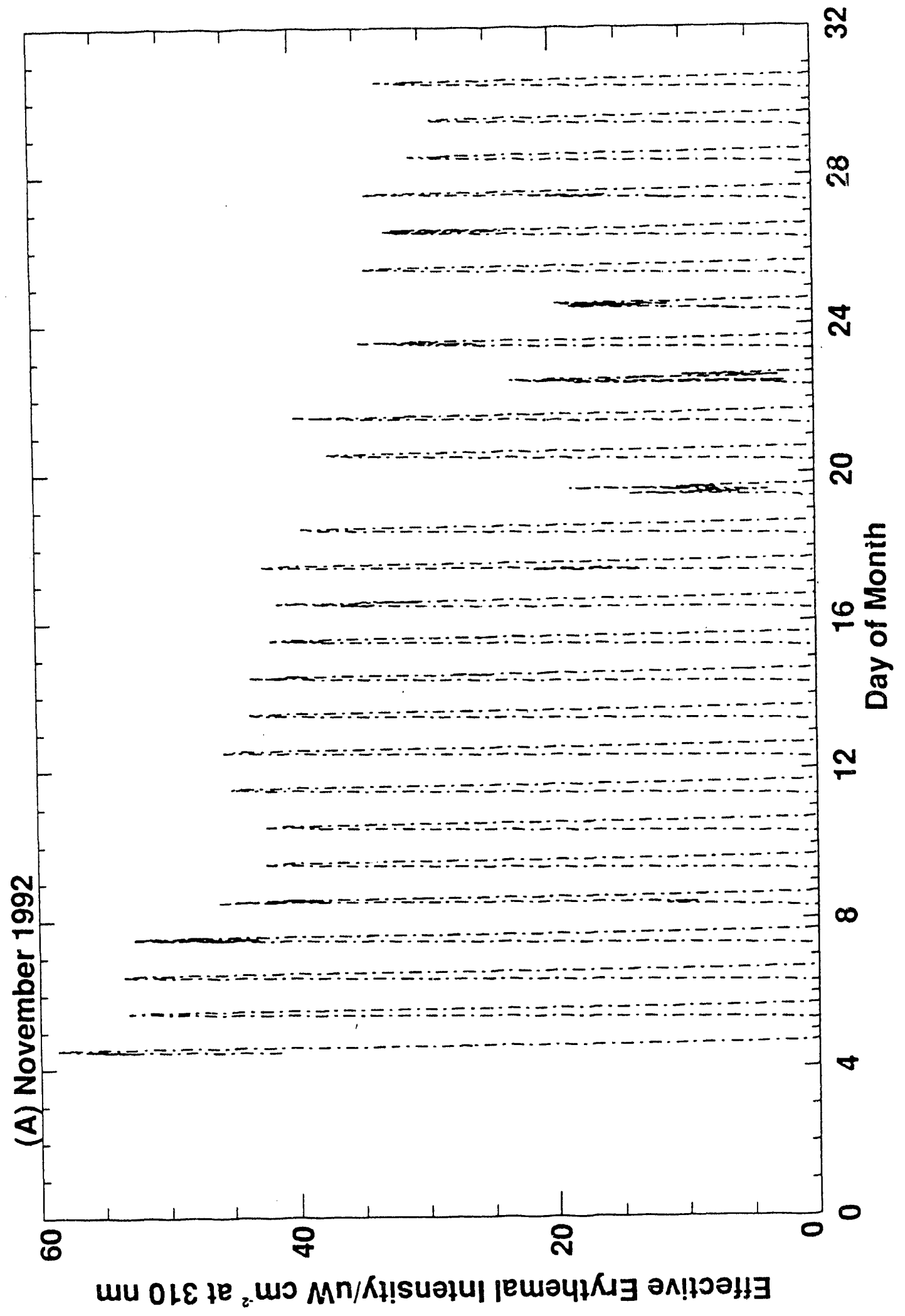




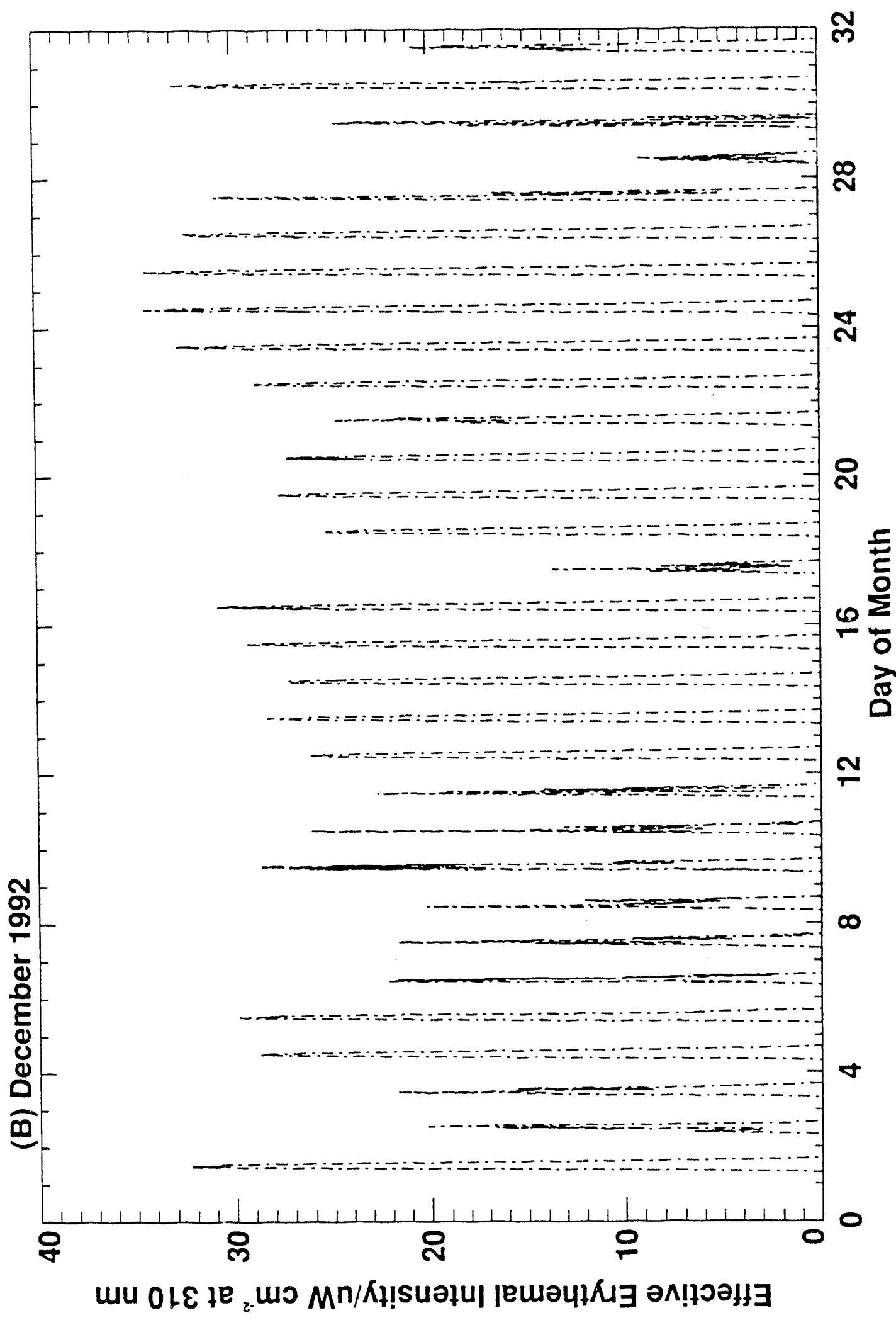

$a$ 


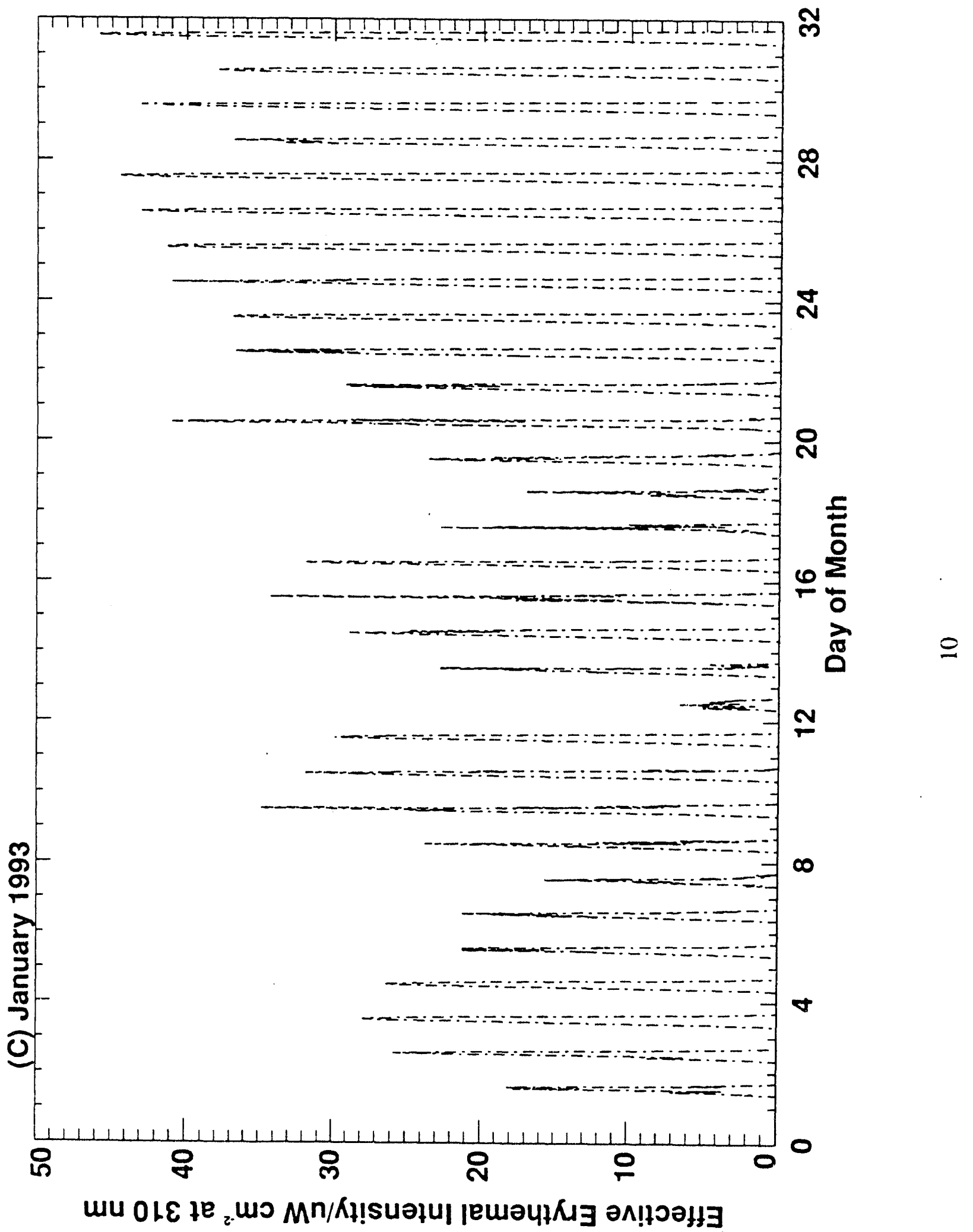




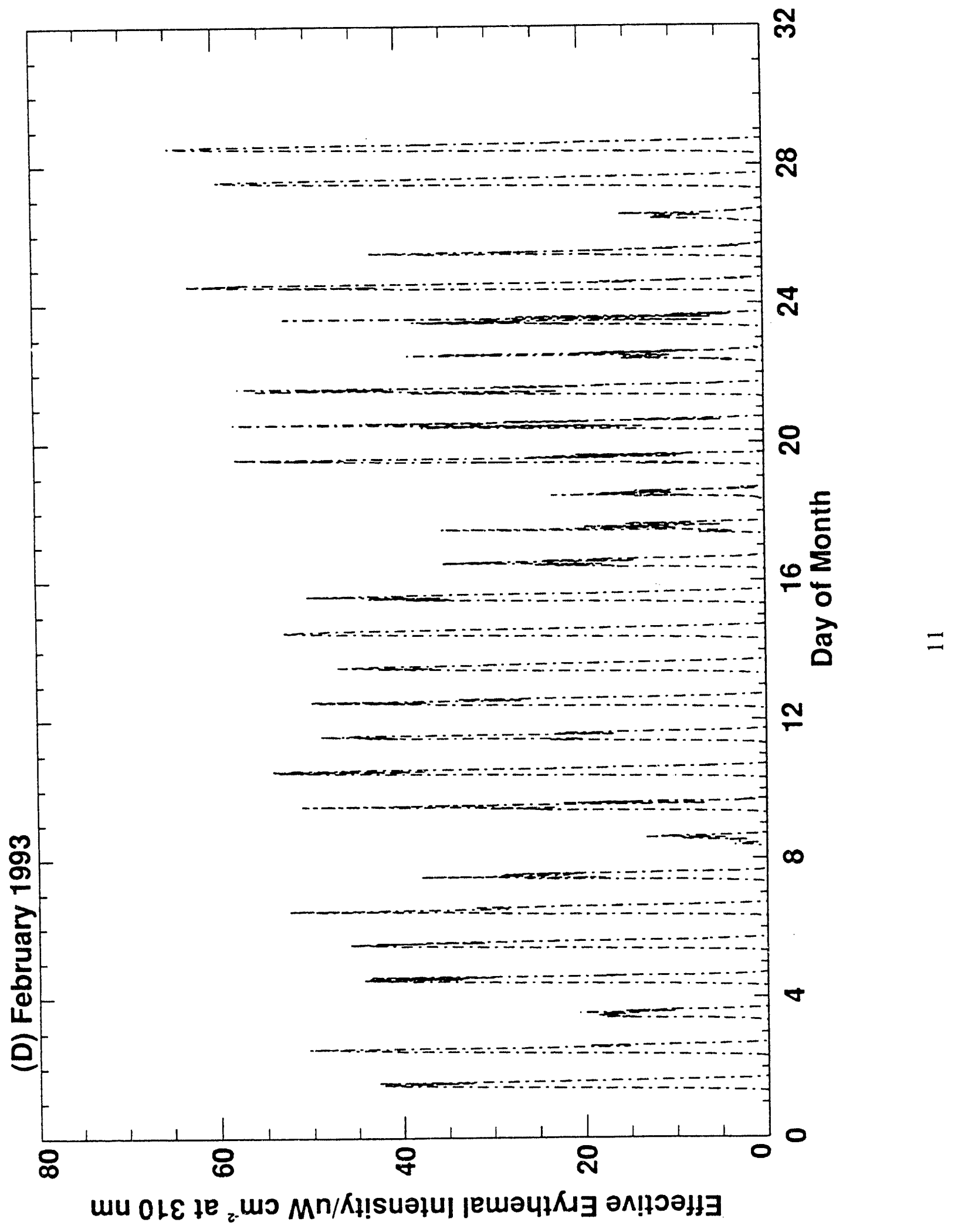




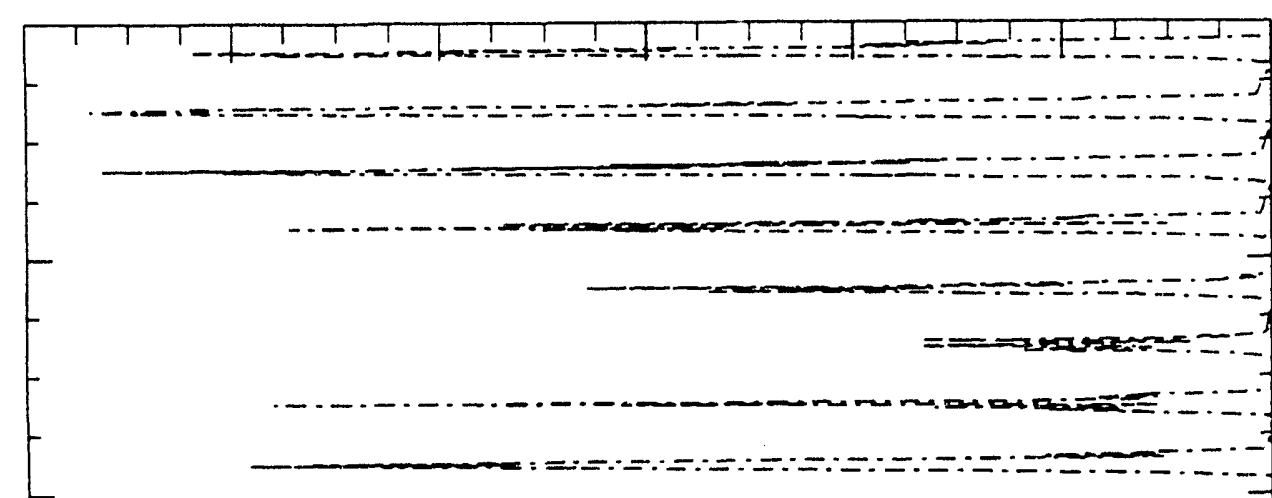

ले

$\stackrel{\infty}{\infty}$

- $\rightarrow$ ser $=-1-7$

$\stackrel{\sim}{\sim}$

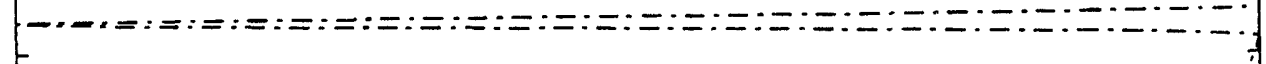

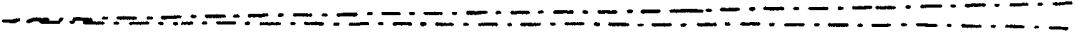

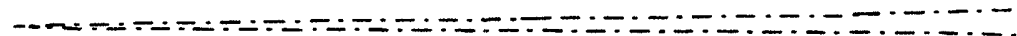

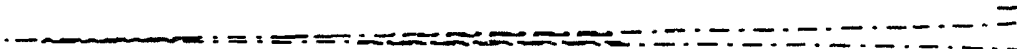

오
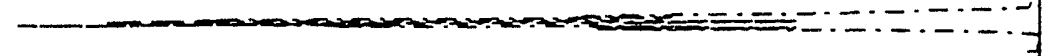

$\cdots \frac{\text { 들 }}{\frac{2}{2}}$

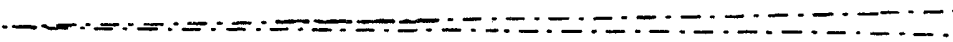

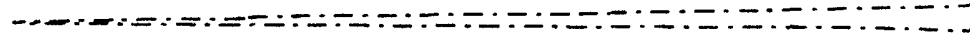

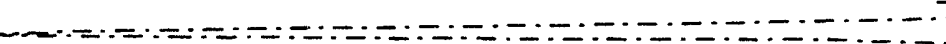

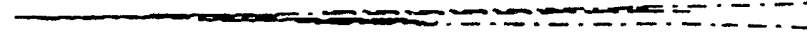
-

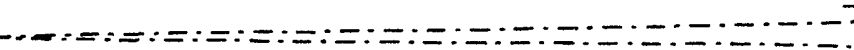

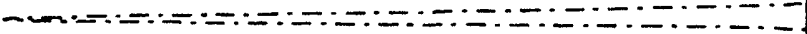

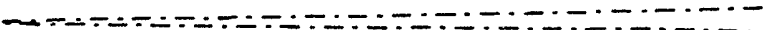

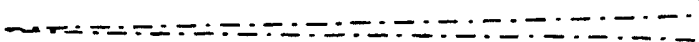

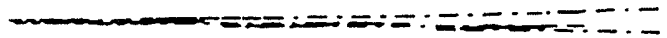

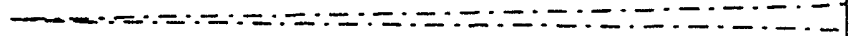

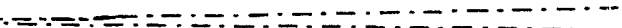

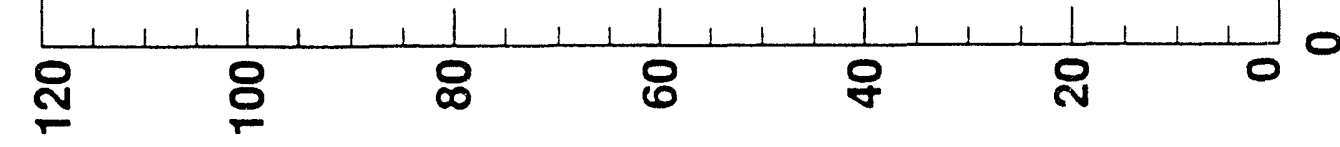

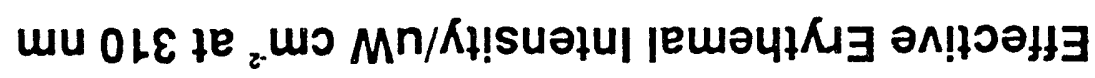




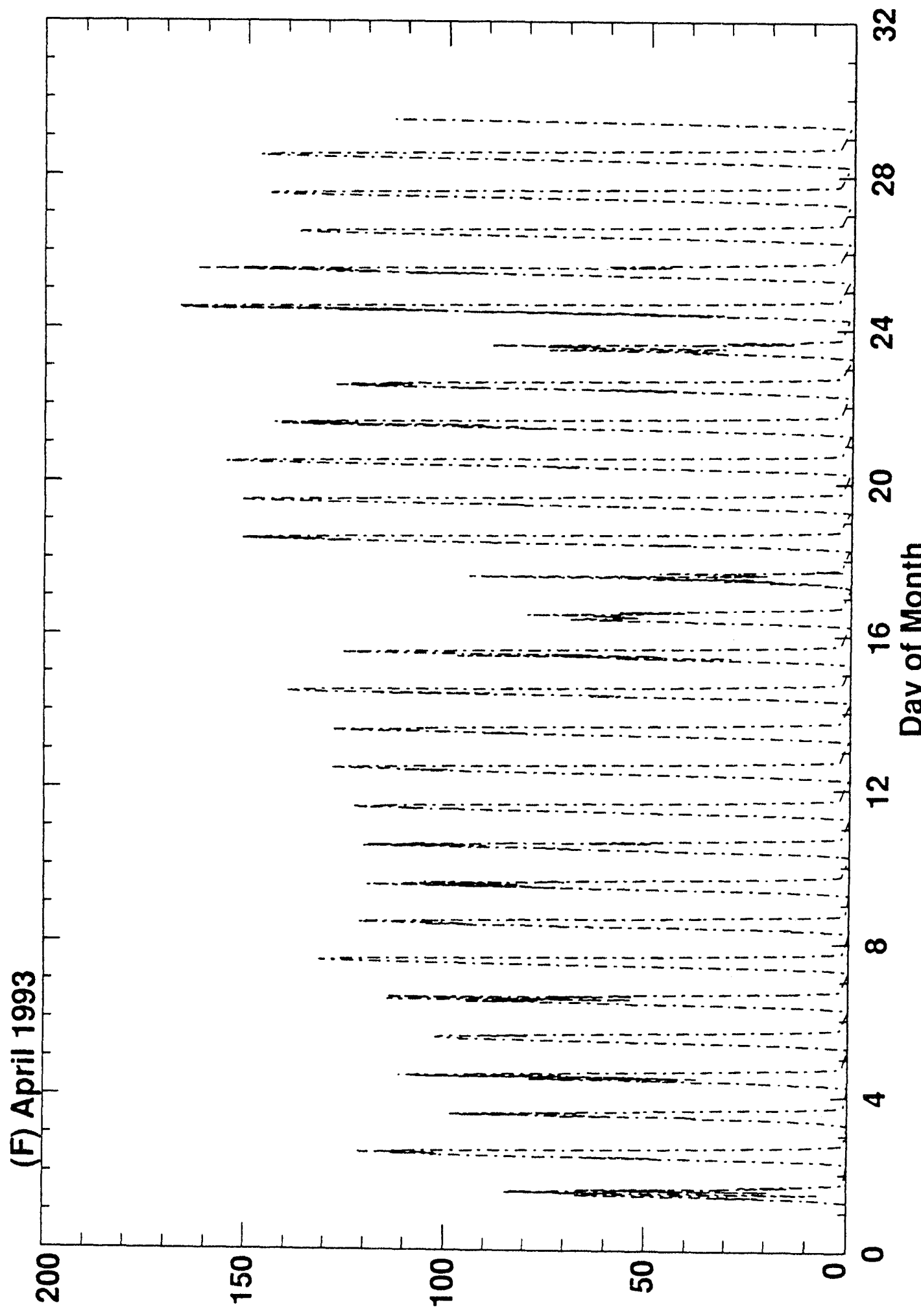

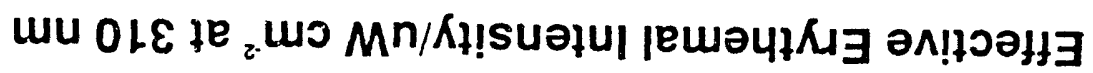




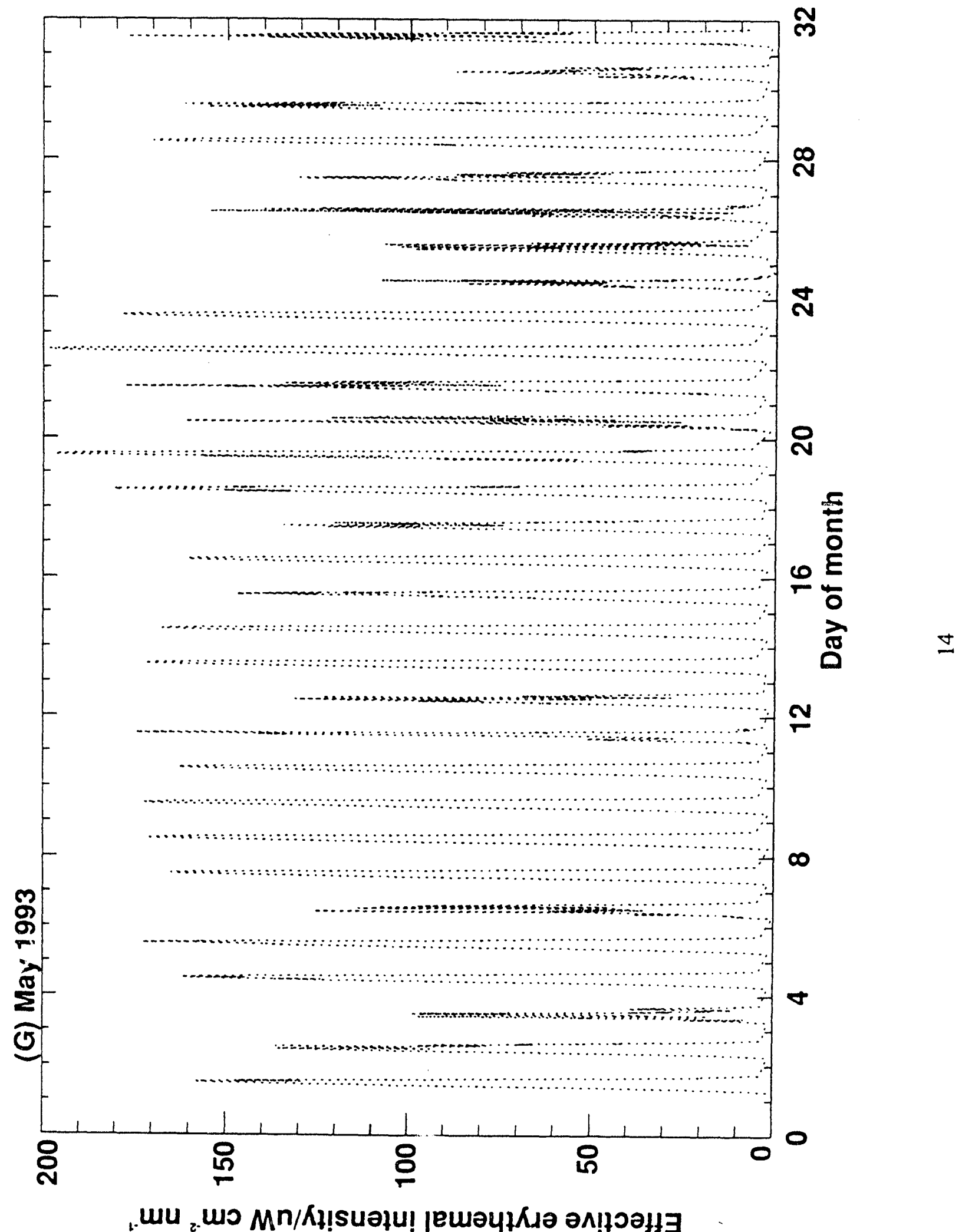




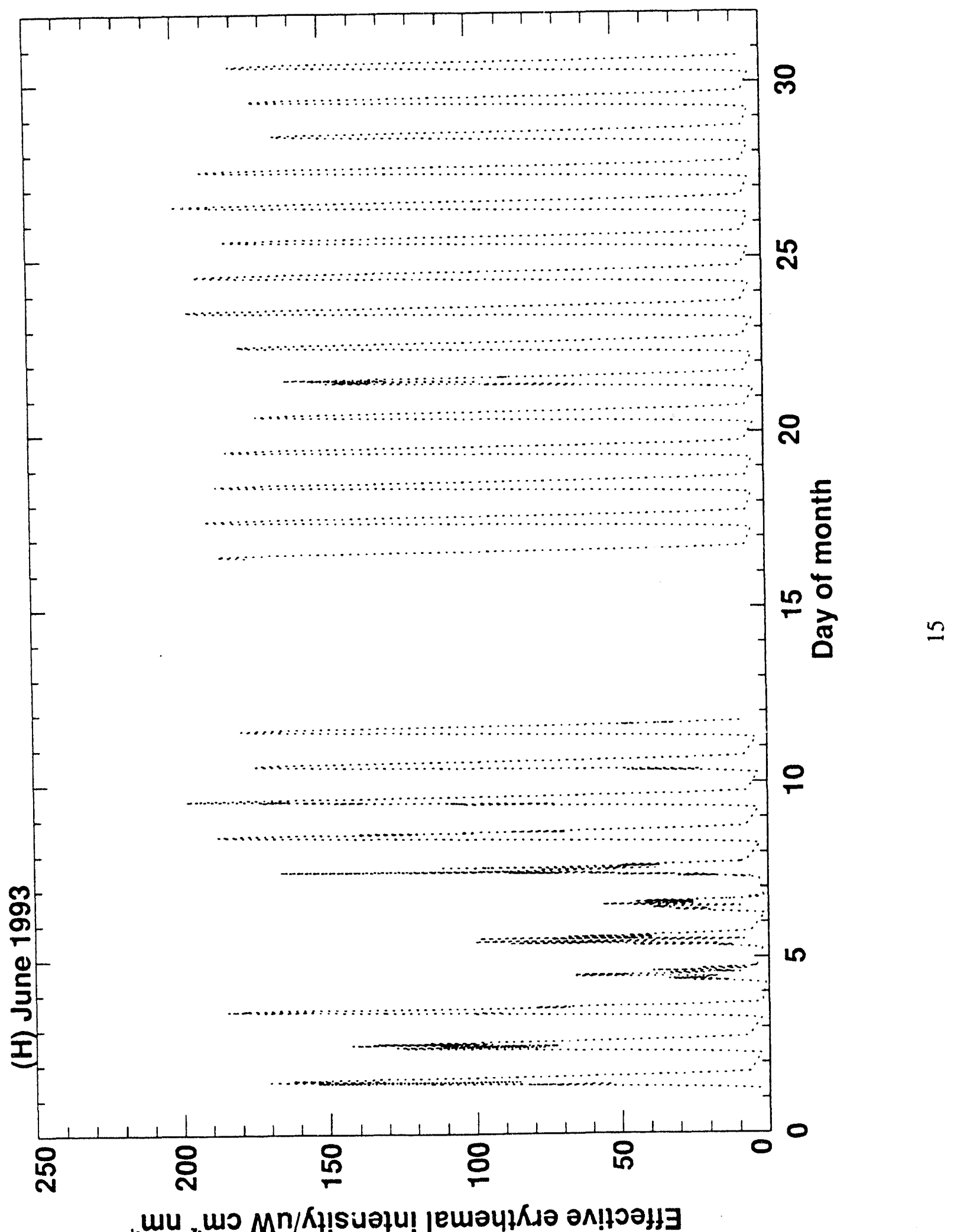




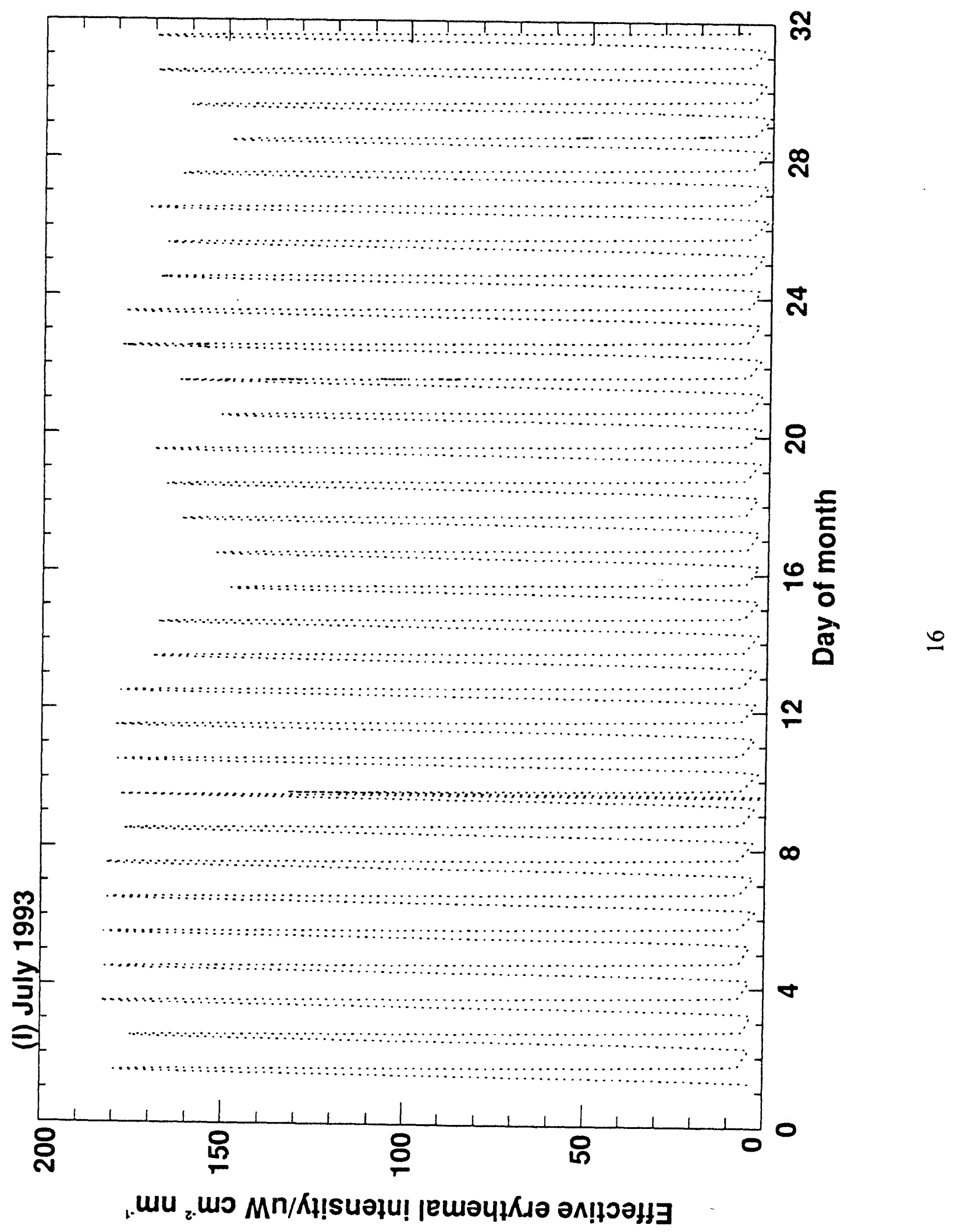




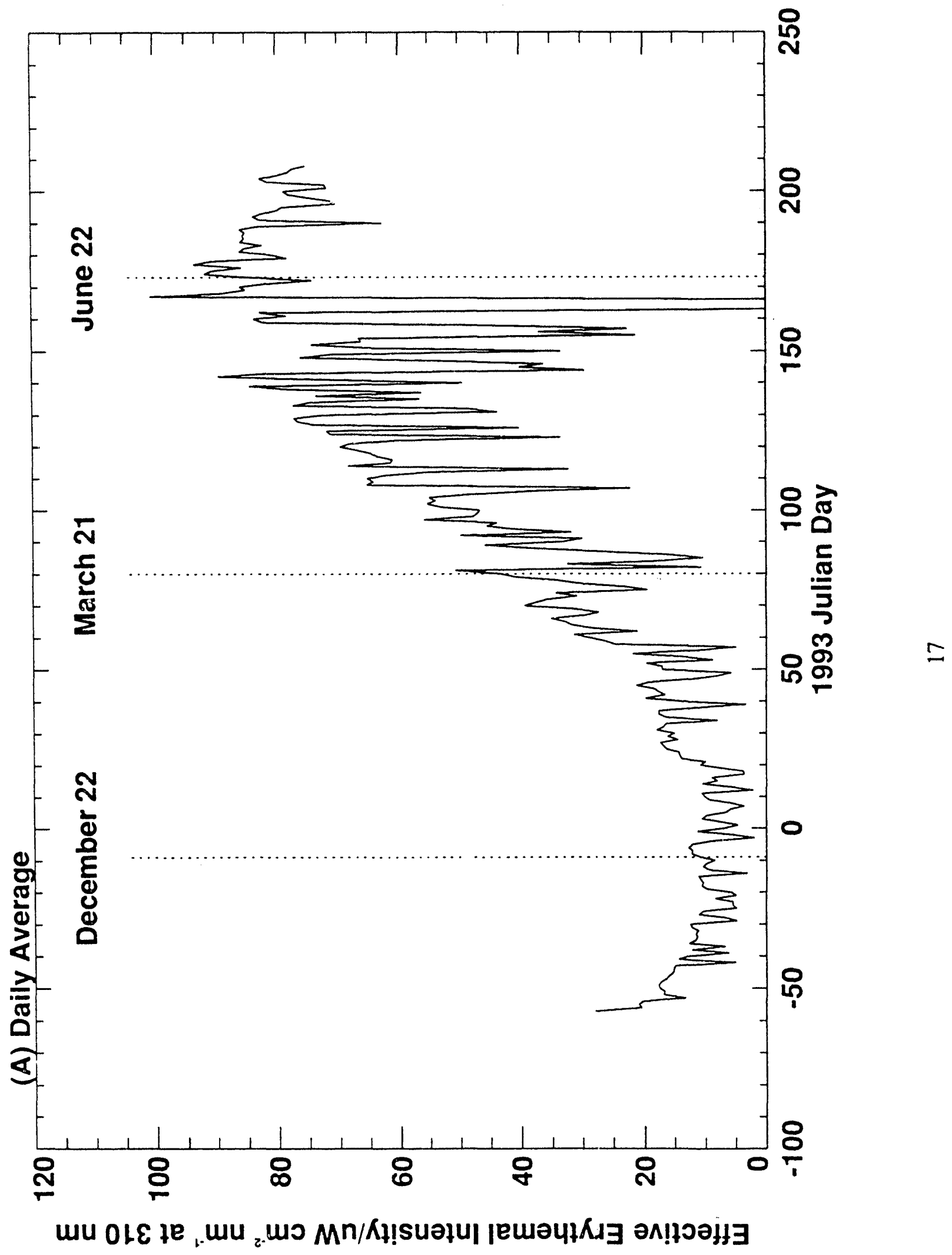




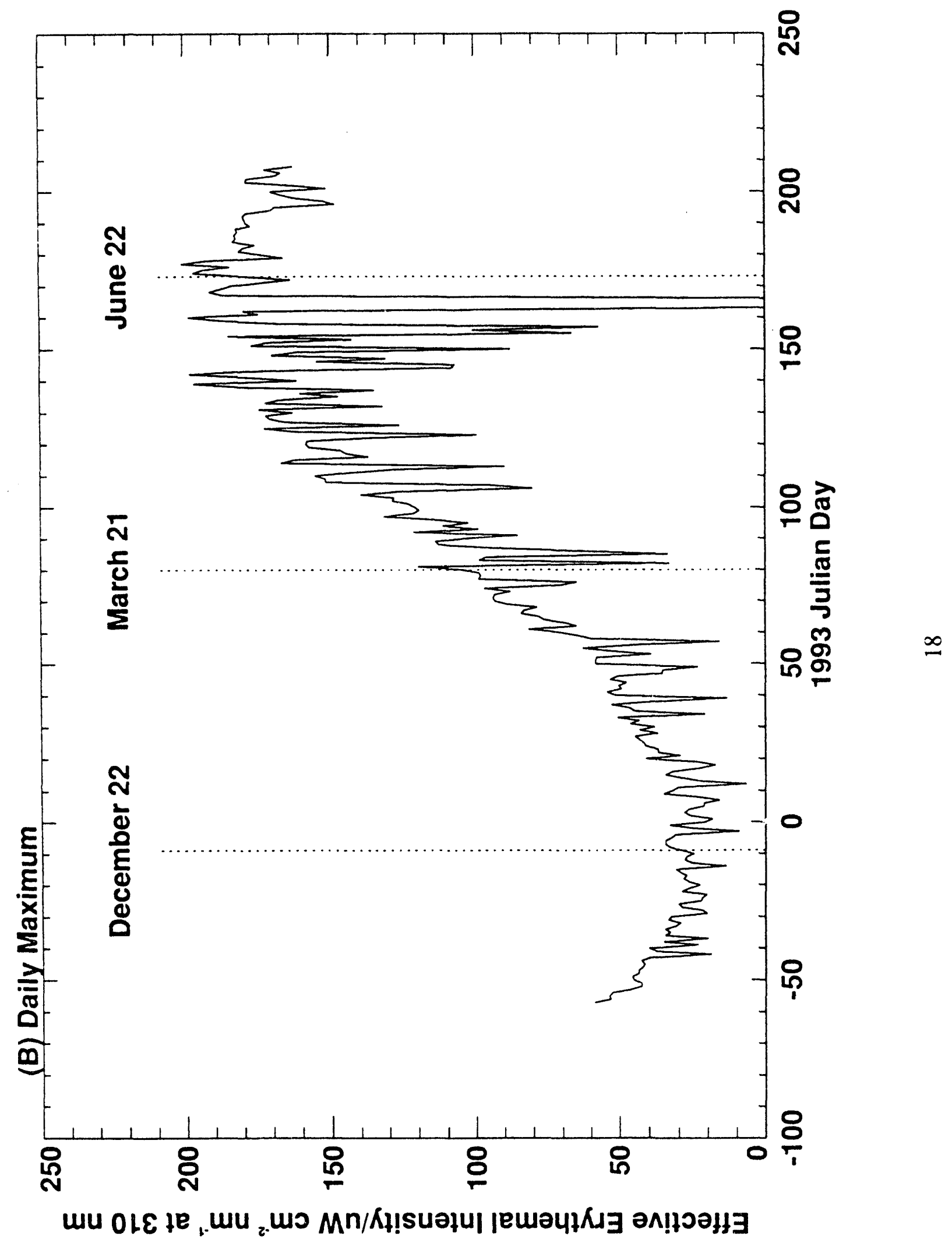




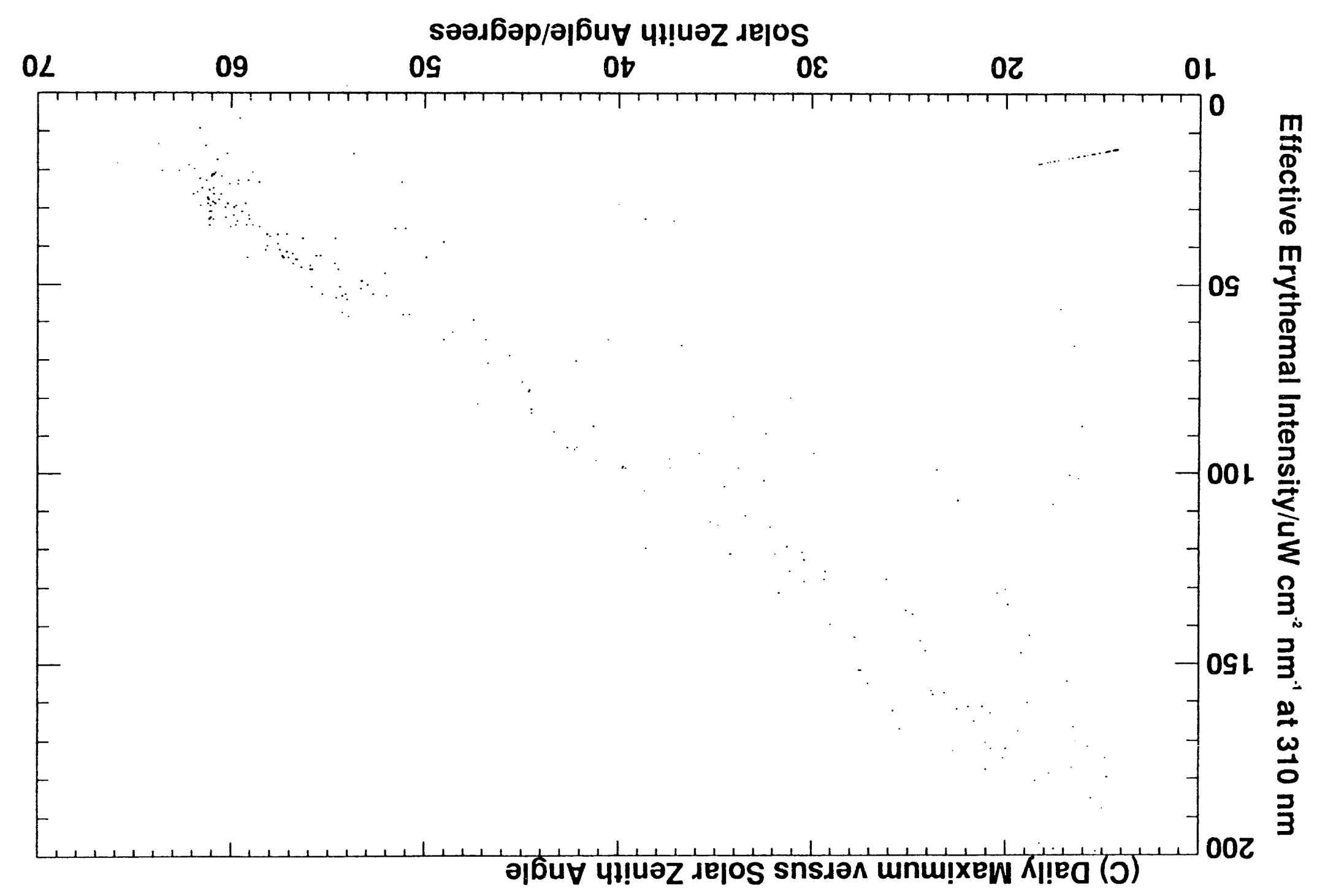




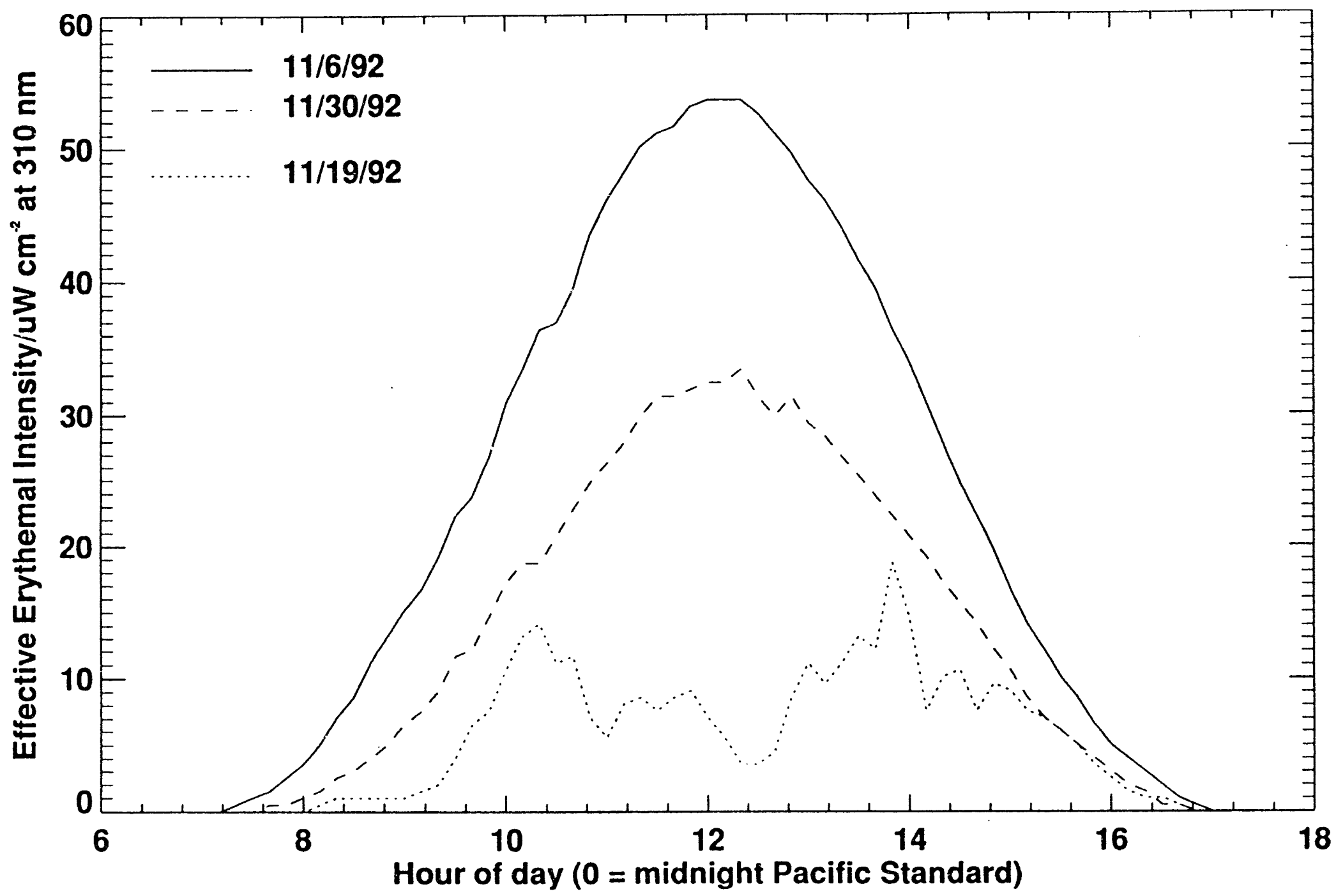




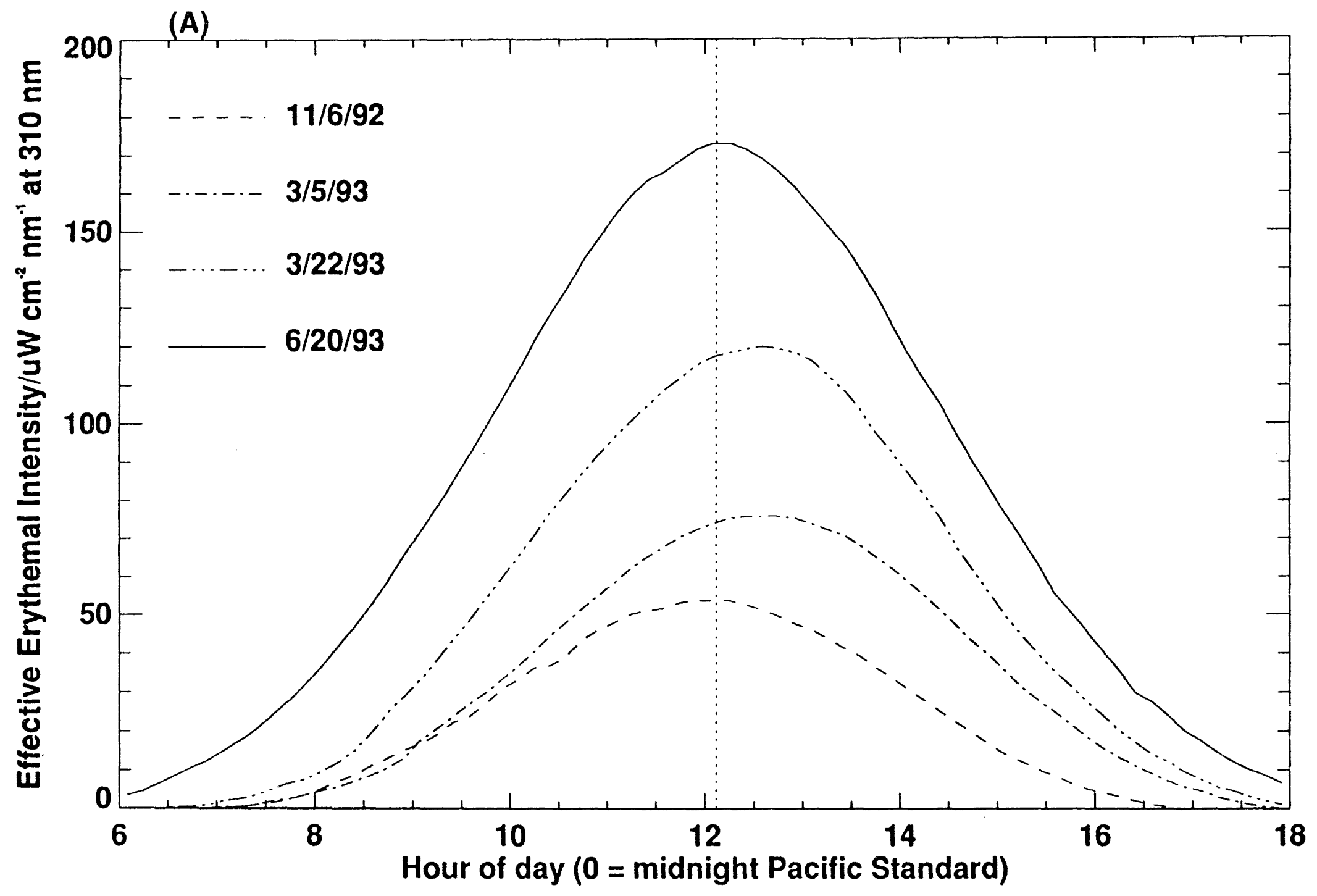




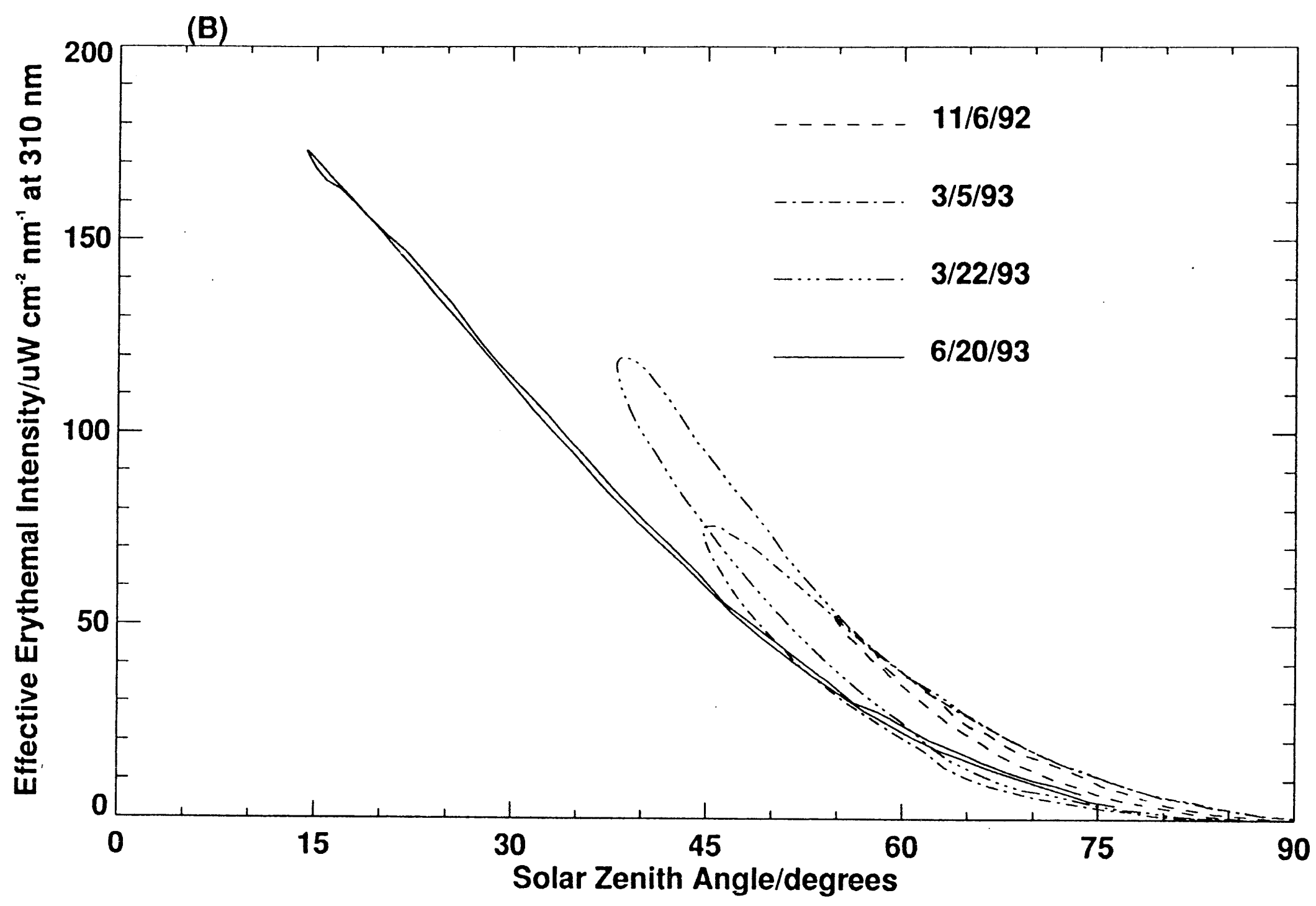




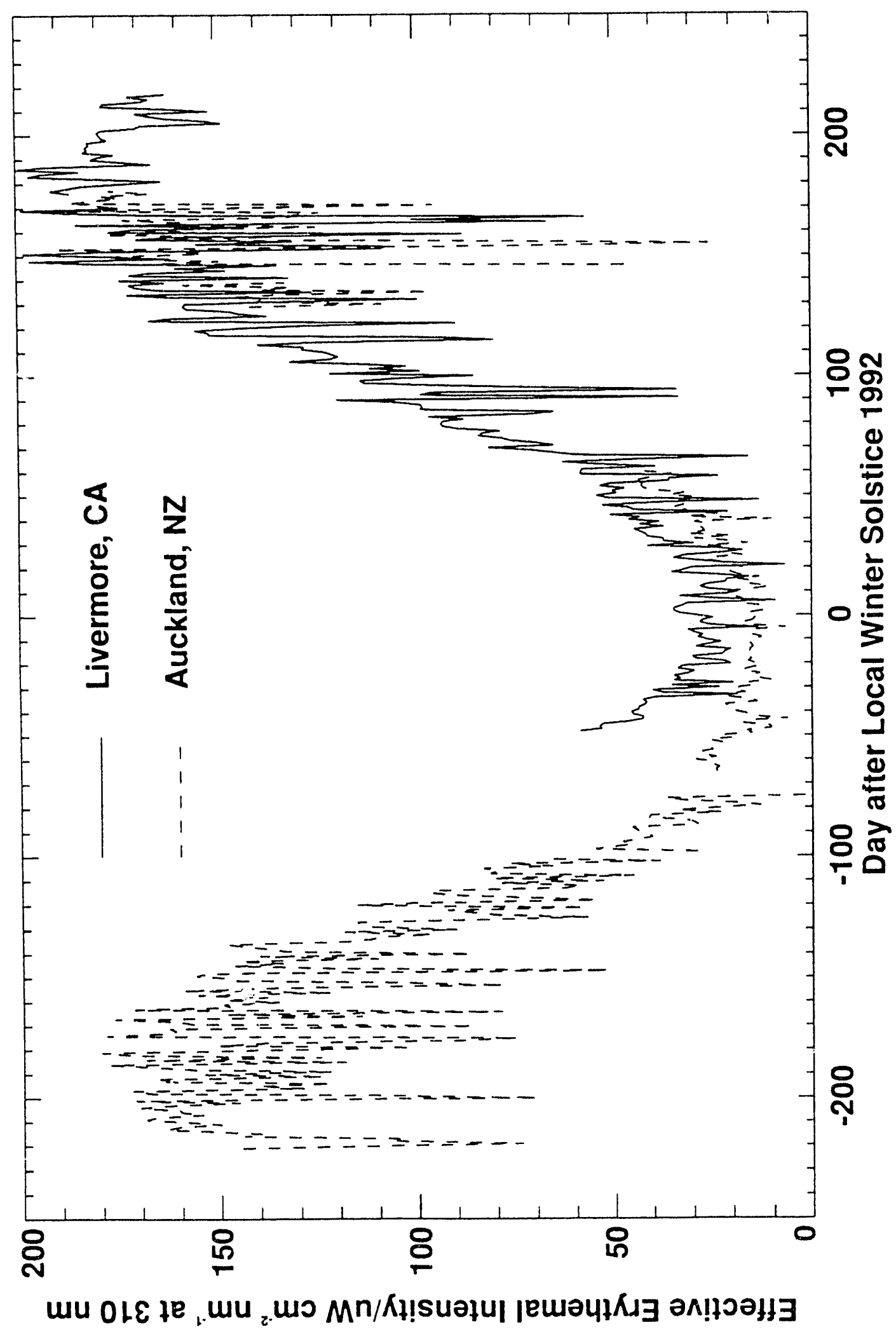

๙ 

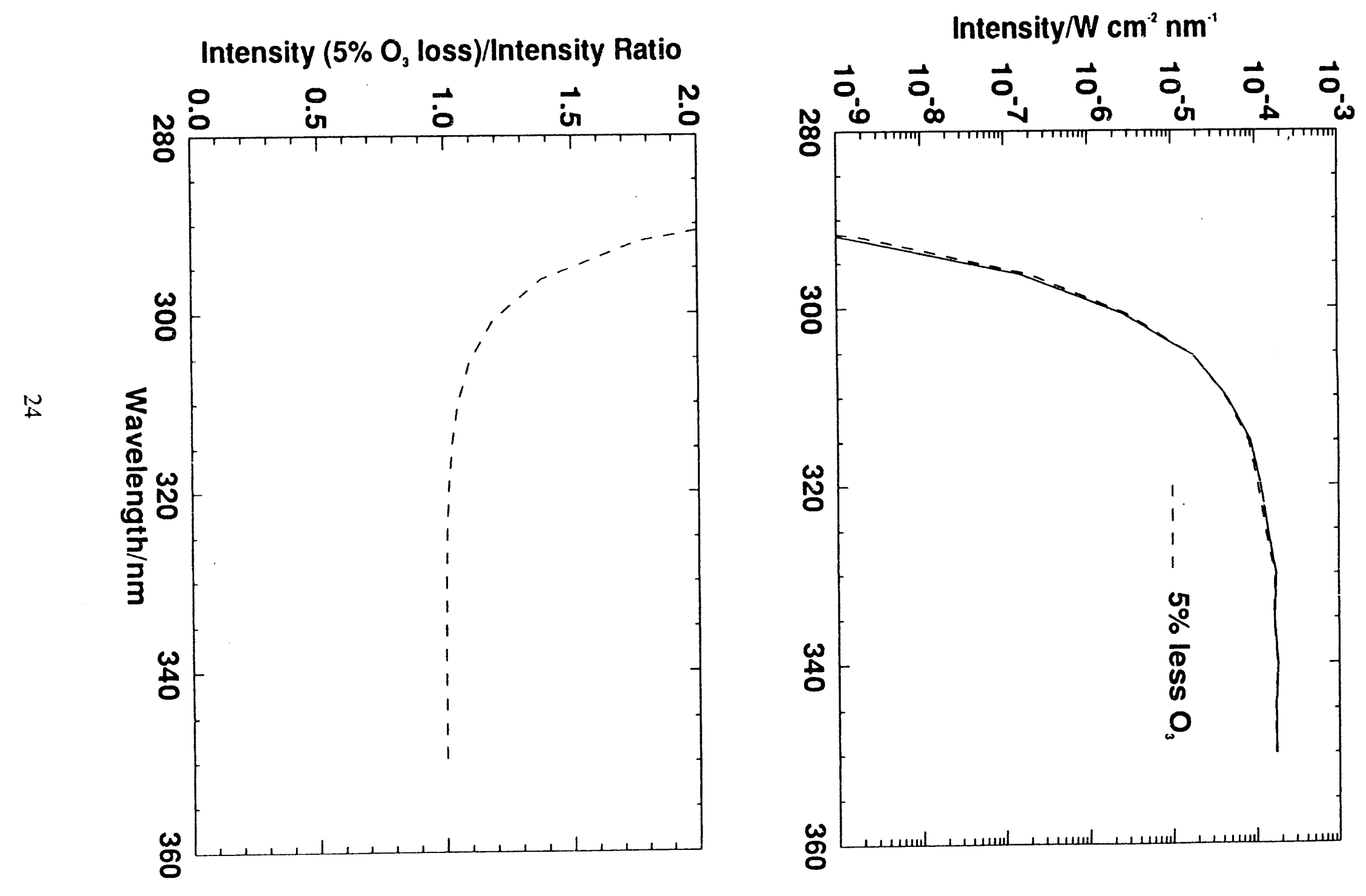


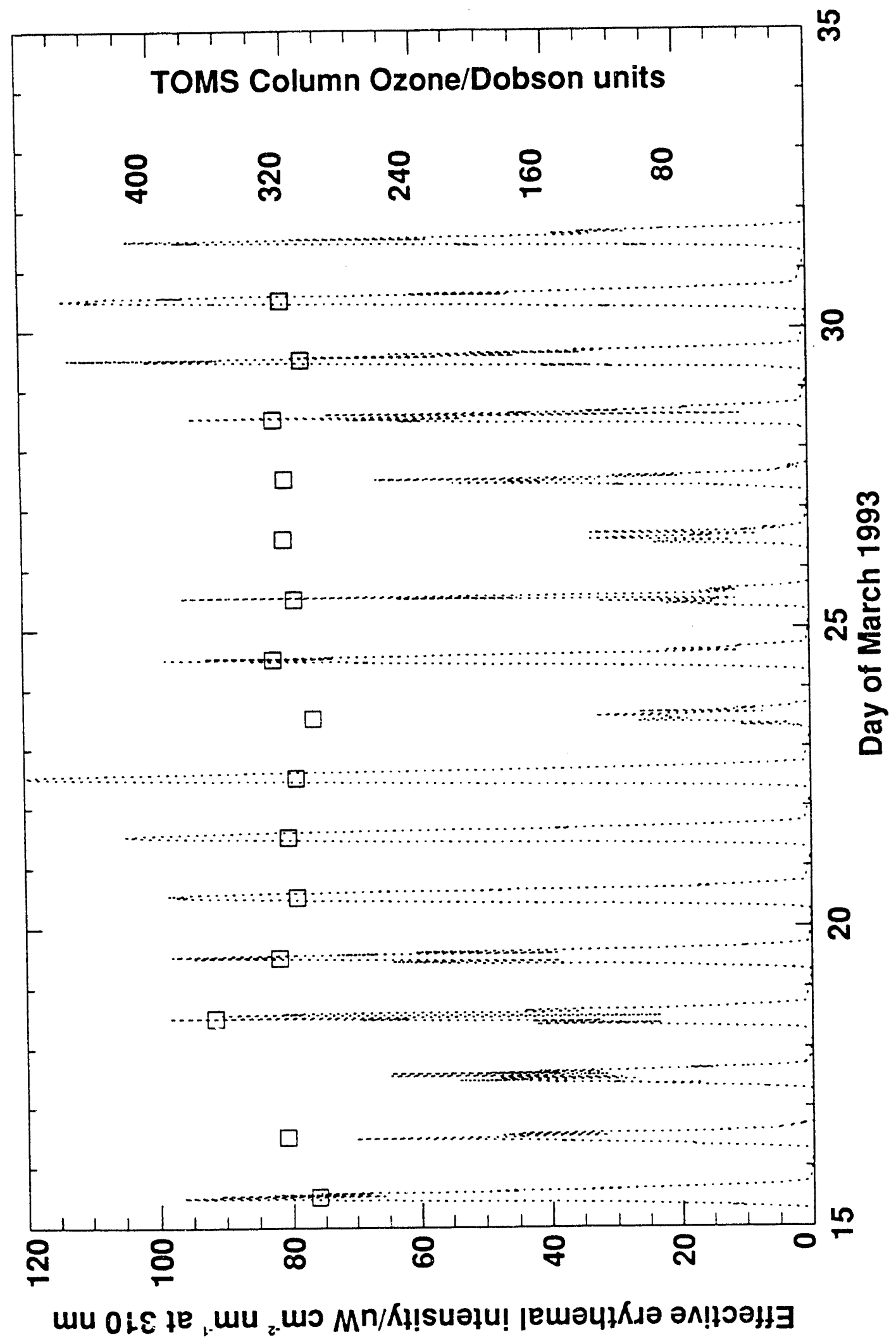



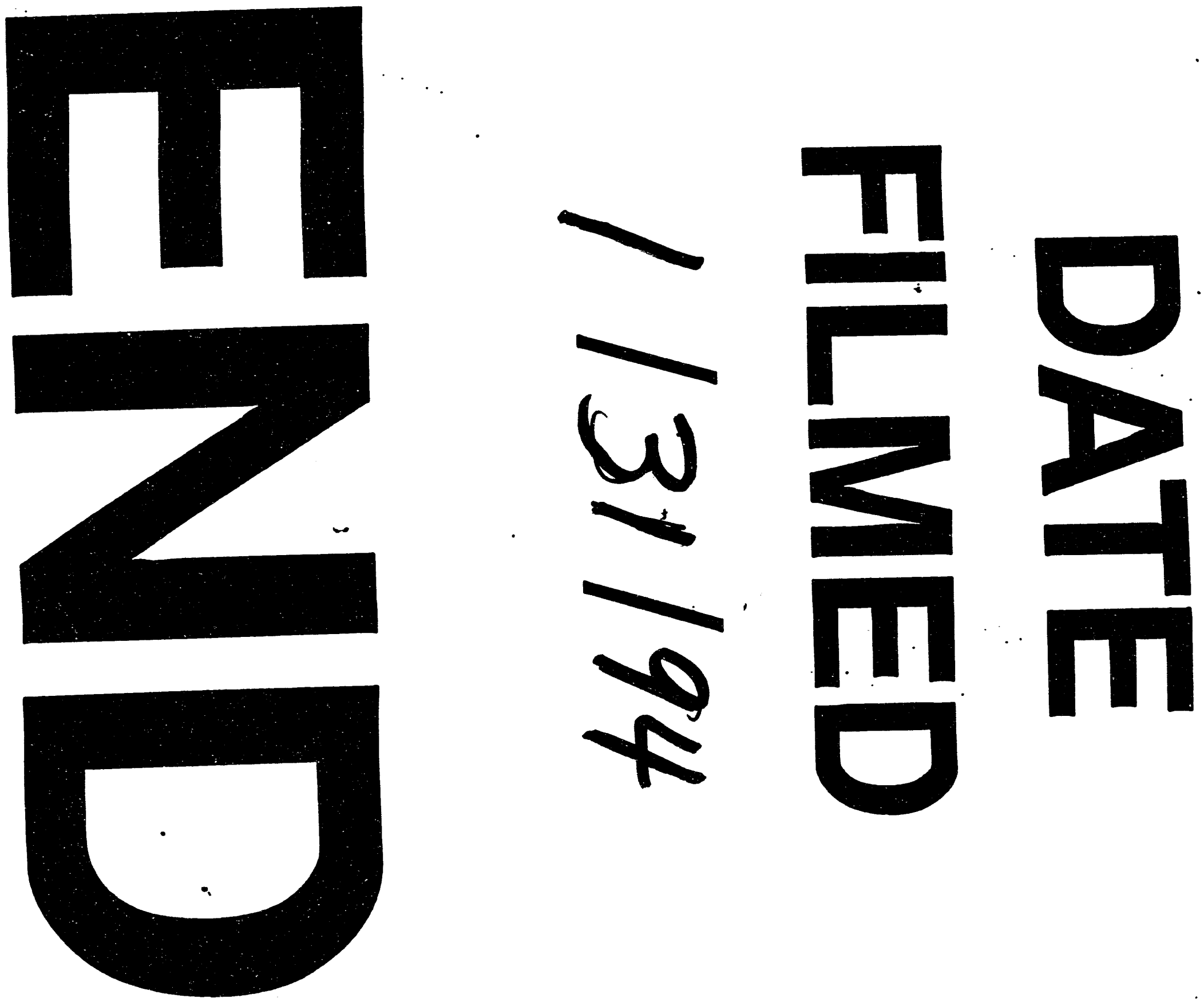


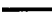
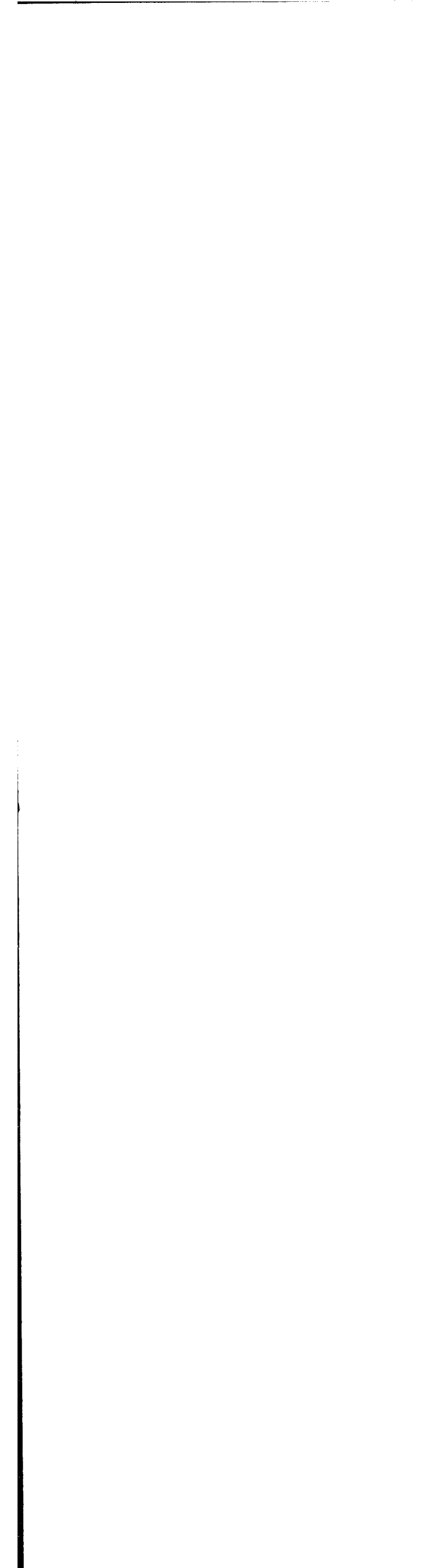